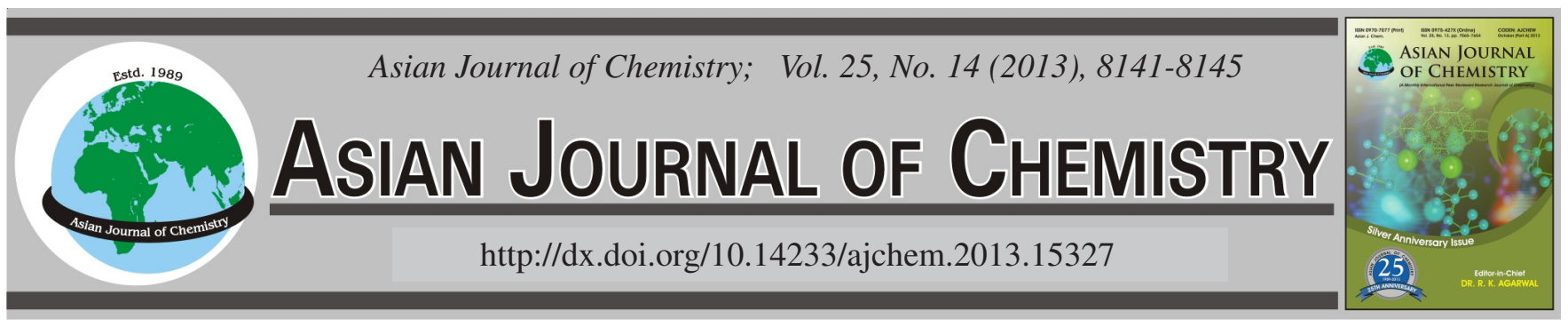

\title{
Qualitative Determination of Known Thromboxane Receptors in Human Plasma by LC-MS (Quadrupole Time of Flight)
}

\author{
Kotte Subhash Chandra Bose ${ }^{1, *}$, P.K. Dubey ${ }^{2}$ and P.M. Murali ${ }^{1}$
}

${ }^{1}$ Evolva Biotech Private Limited, TICEL Bio Park Limited, Taramani, Chennai-600 113, India

${ }^{2}$ Department of Chemistry, College of Engineering, Jawaharlal Nehru Technological University-Hyderabad, Kukatpally, Hyderabad-500 085, India

*Corresponding author: Tel/Fax: +91 44 42971050/60; E-mail: subhashcbk@gmail.com

(Received: 13 February 2013;

Accepted: 5 August 2013)

AJC-13891

\begin{abstract}
A simple, rapid and sensitive reverse-phase LC-MS method has been developed for the simultaneous quantification of Dazmegrel, GR 32191, SQ-29548 and U-46619 in human plasma. Analytes were extracted from human plasma by liquid-liquid extraction technique using acetonitrile. Separation was achieved on a reverse phase Shodex C18, $3 \mu \mathrm{m}, 4.6 \times 100 \mathrm{~mm}$ column at ambient temperature under isocratic conditions at a flow rate of $1 \mathrm{~mL} / \mathrm{min}$, run time of $10 \mathrm{~min}$ with acetonitrile and $0.1 \%$ formic acid in water (70:30 v/v). Detection was performed using dual electrospray ionization (ESI) by using a fast polarity switch mode for fragment ions and adduct as for Dazmegrel, GR32191, SQ-29548 and U-46619 in positive and negative modes. The results indicate that this proposed method is convenient and reliable for clinical studies application.
\end{abstract}

Key Words: Dazmegrel, GR32191, LCMS, SQ-29548, Thromboxane receptors, U-46619.

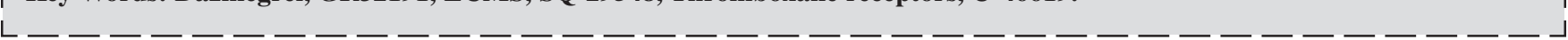

\section{INTRODUCTION}

Thromboxane is a potent platelet aggregating agent which also contracts both vascular and non-vascular smooth muscle. Selective agents have been identified which inhibit these actions of thromboxane in a manner consistent with competitive receptor antagonism. Some of these antagonists have potential utility in the treatment of thromboxane-dependent pathologies, particularly within the cardiovascular/renal systems.

Classically, receptor types are defined by use of selective antagonists and possible receptor differences derived from differential potency of these antagonists when measured in different tissues. Dazmegrel ${ }^{1-3}$ [3-(1H-imidazole-1-yl-methyl)2-methyl-1H-indole-1-propanoic acid] is persistence as enzyme inhibitors; platelet aggregation inhibitors and Vasodilator Agents. GR32191-10 (vapiprost) 7-(5-(((1,1'-biphenyl)-4-yl)methoxy)-3-hydroxy-2-(1-piperidinyl)cyclopentyl)-4-heptanoic acid is a potent and selective thromboxane receptor antagonist. The thromboxane A2/PG endoperoxide receptor inhibitor. Its mechanism is Fibrinolytic Agents; platelet aggregation inhibitors and prostaglandin antagonists. SQ $29548^{11} 7-(3-((2-$ ((phenylamino)carbonyl)hydrazine)methyl)-7-oxabicyclo(2.2.1)hept-2-yl)-5-heptenoic acid is a Thromboxane/antagonists \& inhibitors. U-46619 ${ }^{12-16}$ (Z)-7-((1R,4S,5S,6R)-6-((E)-3hydroxyoct-1-enyl)-2-oxabicyclo[2.2.1] heptan-5-yl)hept-5- enoic acid has been postulated to inhibit platelet aggregation by competitively interfering with the thromboxane A2 (TxA2) platelet receptor, which was found to be able to displace the platelet binding and a labeled TxA2 antagonist. A stable prostaglandin endoperoxide analog which serves as a thromboxane mimetic. Its actions include mimicking the hydroosmotic effect of VASOPRESSIN and activation of TYPE C PHOSPHOLIPASES.

Literature survey revealed that no method has been reported till date for determination of Dazmegrel, GR 32191, SQ-29548 and U-46619 in human plasma. As per ICH guidelines here we are reporting the availability of structurally different thromboxane receptor antagonists has allowed analysis of thromboxane receptors characteristics in human plasma by using Accurate Mass Q-TOF LC/MS. The proposed LCMS method was validated by assessing its specificity, linearity, accuracy, precision, limits of detection and quantification, system suitability parameters, ruggedness and robustness. This article reports for the first time the results of a study carried out to develop a straightforward HPLC PDA-ESI-MS method, which employs liquid-liquid extraction technique for sample preparation and simultaneous identification and quantification of Dazmegrel, GR 32191, SQ-29548 and U-46619 in human plasma, thus the proposed method can be used for routine analysis in clinical trials. 
<smiles>Cc1c(Cn2ccnc2)c2ccccc2n1CCC(=O)O</smiles>

(1)<smiles>O=C(O)CCC/C=C\CC1C2CCC(O2)C1CNNC(=O)Nc1ccccc1</smiles>

(3)

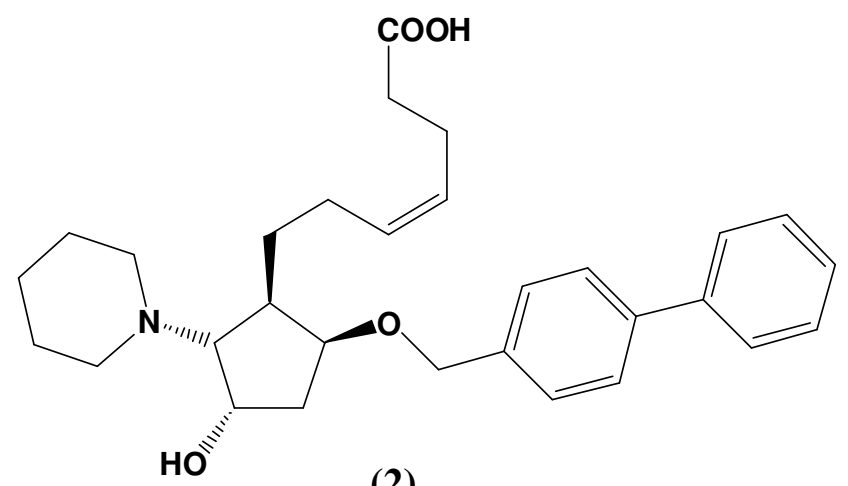

(2)

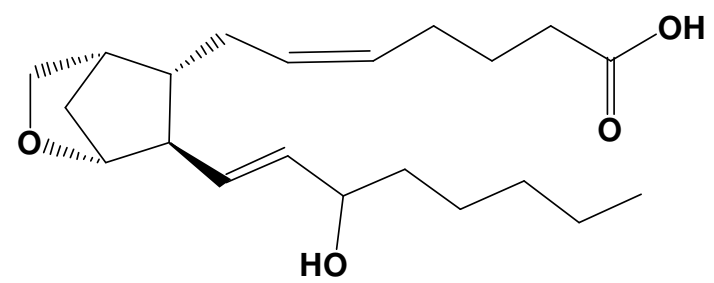

(4)

\section{EXPERIMENTAL}

Pure standards of SQ-29548, U-46619, GR32191 and Dazmegrel were obtained from the TOCRICS and ALEXIS. All the chemicals used were of analytical reagent grade and the solvents were of ACS in LCMS grade, HPLC Ultra Gradient Solvent Acetonitrile BAKER ANALYZEDR $®$ was purchased from J.T. Baker, Avantor Performance Materials (USA), ultrapure water was obtained using an Elix Advantage 5 system coupled to a Milli-Q Biocel (Billerica, MA, USA). All solutions were degassed by ultrasonic cleaner using KUDOS (Shanghai, P.R.China) and filtered through Millex-FG Filter, $0.20 \mu \mathrm{m}$, Fluropore $^{\mathrm{TM}}$ (PTFE) $13 \mathrm{~mm}$, non-sterile membrane sample filter before injecting into system. Drug-free human plasma was obtained from the Holy mother diagnostics and Blood Bank (Madipakkam, Chennai, India).

LC-MS conditions and accurate-mass spectrometry quadrupole time of flight: The LC method was carried out using an Agilent 1200 series HPLC system (Agilent Technologies, USA), equipped with a binary pump, a degasser, PDA detector, an auto-sampler, a column oven. The separation was carried out on a reverse phase Shodex C18 - 4C, $3 \mu \mathrm{m}, 4.6 \times 100 \mathrm{~mm}$ at ambient temperature. A security guard holder was used to protect the analytical column. Isocratic elution was employed using $0.1 \%$ formic acid in water (solvent $\mathrm{A}$ ) and Acetonitrile (solvent B) (70:30 (v/v) and eluted by the following program at the flow $1 \mathrm{~mL} / \mathrm{min}$ with run time of $10 \mathrm{~min}$.

Agilent 6520 Quadrupole time-of-flight (Q-TOF) mass spectrometer coupled to an Agilent 1200 series HPLC system. The Agilent's Q-TOF mass spectrometer is equipped with dual electrospray ionization (ESI) ion source. Precisely mass spectra were acquired by using fast polar switching mode with scan range from m/z 100 to $600 \mathrm{Da}$. The conditions of dual ESI source were as followed: drying gas $\left(\mathrm{N}_{2}\right)$ flow rate, $30 \mathrm{~L} / \mathrm{min}$; temperature, $350{ }^{\circ} \mathrm{C}$; pressure of nebulizer, $50 \mathrm{psi}$; capillary voltage, $3500 \mathrm{~V}$, drying gas $10 \mathrm{~L} / \mathrm{min}$ and fragmentor voltage, $175 \mathrm{~V}$ and MS parameters are showed in Table-1. Data were acquired and analyzed by Agilent Mass Hunter Workstation Software version B.02.01 (B2116.20) and Quantitative Analysis Version B.01.04 (B 1.4.126.0) (Agilent Technologies, USA). The output signal is monitored and processed using mass hunter software on Intel ${ }^{\circledR}$ Core (TM) 2 Duo computer (HP xw 4600 Workstation). This instrument was used to confirm the identification of chromatographic peaks of interest.

\begin{tabular}{ll}
\multicolumn{1}{c}{$\begin{array}{c}\text { TABLE-1 } \\
\text { MS PARAMETERS }\end{array}$} \\
\hline Capillary voltage (V cad) & $3500 \mathrm{~V}$ \\
Fragmentor & $175 \mathrm{~V}$ \\
Gas flow & $10 \mathrm{~L} / \mathrm{min}$ \\
Gas temperature & $350^{\circ} \mathrm{C}$ \\
Ionization mode & Dual ESI fast polarity \\
Nebulizer & $50 \mathrm{psi}$ \\
Octo dole RF peak & $750 \mathrm{~V}$ \\
Scan rate & 0.8 spectra/s \\
Skimmer & $65 \mathrm{~V}$ \\
\hline
\end{tabular}

Preparation of standard stock solutions: Mixed standard stock solutions were prepared by accurately weighed the all standards and dissolved in suitable solvent (methanol). The working standard solution was prepared by diluting the mixed standard solution with the same to a series of proper concentrations. The standard stock and working solutions were all stored at $4{ }^{\circ} \mathrm{C}$ until use.

Preparation of plasma samples: A $50 \mu \mathrm{L}$ aliquot of the premix stock solution was added into $200 \mu \mathrm{L}$ of drug free human plasma and samples were mixed for 3 min by vortex, add $200 \mu \mathrm{L}$ of acetonitrile to crash proteins and centrifuged at $14000 \mathrm{rpm}$ for $10 \mathrm{~min}$. The organic layer was transferred to a 
test tube and evaporated to dryness under a stream of nitrogen at $40{ }^{\circ} \mathrm{C}$. The residue was reconstituted in $100 \mu \mathrm{L}$ of mobile phase. After centrifugation at $14000 \mathrm{rpm}$ for $2 \mathrm{~min}, 2 \mu \mathrm{L}$ of the supernatant was subjected to analysis.

Calibration curves: The working standard solutions were brought to room temperature and an aliquot of $2 \mu \mathrm{L}$ was injected into LC-MS for the construction of calibration curves. Eleven concentrations in triplicate were analyzed and the calibration curves were calculated by linear regression of the double logarithmic plots of the peak area versus the amount of thromboxane receptors injected.

Limits of detection and quantitation: The limits of detection (LODs) and quantification (LOQs) under the present chromatographic conditions were determined by diluting the standard solution when the signal-to-noise ratios $(\mathrm{S} / \mathrm{N})$ of analytes were almost 3 and 10, respectively. The $\mathrm{S} / \mathrm{N}$ was calculated as the peak height divided by the background noise value. The background noise was measured from the background start to background end time.

Precision, repeatability and accuracy: Intra and interday variations were chosen to determine the precision of the developed method. For intra-day variability test, the working standard solutions (at low, medium and high levels of concentration) were analyzed in triplicate three times within one day, whereas for inter-day variability test, the working solutions were examined in triplicate for consecutive 3 days. Variations of the peak area were taken as the measures of precision and expressed as percentage relative standard deviations (R.S.D.).

For repeatability test, six independent analytical sample solutions from the same batch were used. R.S.D. (\%) values of the obtained contents of each analyte were used to estimate repeatability.

Robustness: Robustness of the method was studied by deliberately changing the experimental conditions like flow rate, percentage of organic phase, $\mathrm{pH}$ of mobile phase and also by observing the freeze and thaw process of the sample solution at $0 \pm 2{ }^{\circ} \mathrm{C}$ for $24 \mathrm{~h}$.

\section{RESULTS AND DISCUSSION}

Method development by LC-MS-dual ESI: The novel and new chromatographic conditions for determination of thromboxane receptors by HPLC- ESI-MS were used and mass parameters were tuned to fast polarity switching mode for the analytes. Good response was found in positive ionization mode for Dazmegrel, GR32191 and SQ-29548 and negative ionization mode for Dazmegrel, GR32191, SQ-29548 and U-46619. For the purpose of correct identification, a LCMS analysis was performed on sample solutions under the dual ESI-MS fast polarity conditions. Analytes, retention time, fragment ion and adduct ions are summarized in Table- 2 . In positive ion mode, the compounds of interest exhibited mainly protonated ions and adduct ions. Finally, the identified thromboxane receptors by comparing their retention times and MS data with those of reference compounds.

Chromatographic conditions, precisely the composition of the mobile phase, column type, flow rate and column oven temperature was optimized through numerous trials to obtain good resolution and amplified intensity of the signals of the analytes, as well as for the short run time. The presence of a small amount of formic acid in the mobile phase improved the detection of the analytes. It was found that a mixture of the isocratic mobile phase was $0.1 \%$ formic acid in water and acetonitrile (30:70 v/v) could achieve this purpose and was finally adopted as the mobile phase. Shodex C18, $3 \mu \mathrm{m}, 4.6 \times$ $100 \mathrm{~mm}$ column gave good peak shape and response even at lowest concentration level for the analytes. The mobile phase was operated at a flow rate of $1 \mathrm{~mL} / \mathrm{min}$. The retention time of Dazmegrel, GR32191, SQ-29548 and for U-46619 (4.237, $6.635,7.855$ and $8.570 \mathrm{~min}$, respectively) were low enough allowing a run time of $10 \mathrm{~min}$.

Liquid-liquid extraction (LLE) technique was applied for the sample preparation in this work. Liquid-liquid extraction is helpful in producing a spectroscopically clean sample and avoiding the overview of non-volatile components onto the column and MS system and also reducing the experimental cost. System suitability parameters like coefficient factor, resolution, tailing factor, theoretical plates and symmetry are within the range and are described in Table-3. Among the different solvents checked alone and in combination for their suitability, acetonitrile and water was found to be optimal, which can produce a clean chromatogram for a blank sample and yields the highest recovery for the analytes from the plasma.

Linearity, limit of detection and limit of quantification: Linearity was demonstrated by using mass chromatographic data by extraction ion current chromatogram from $10 \mathrm{ppm}$ to $125 \mathrm{ppm}$ of the standard concentration in mixture form using eleven calibration levels $(10,20,30,40,50,60,70,80,90$, 100 and 125 ppm) for Dazmegrel, GR32191, SQ-29548 and U-46619 (Fig. 1). The method of linear regression was used for data evaluation. The peak areas of the standards in mixture form were plotted against the respective standard concentration. Linearity was described by the linearity equation, the correlation coefficient and excellent linearity obtained in above concentrations levels.

TABLE-2

COMPOUNDS SEPARATED (ESI-MS DETECTION), MOLECULAR FORMULA AND MOLECULAR WEIGHT FOR EACH ANALYTE

\begin{tabular}{|c|c|c|c|c|c|c|c|}
\hline Peak No. & Compound & $t_{R}(\min )$ & Molecular mass & Fragment ion $\mathrm{m} / \mathrm{z}$ & Ion & Adduct ion $\mathrm{m} / \mathrm{z}$ & Ion \\
\hline 1 & Dazmegrel & 4.223 & 283.16246 & 282.15197 & (M-H)- & 565.31244 & $2(\mathrm{M}-\mathrm{H})-$ \\
\hline & & & & 284.17010 & $(\mathrm{M}+\mathrm{H})+$ & 567.33745 & $2(\mathrm{M}+\mathrm{H})+$ \\
\hline 2 & GR32191 & 6.651 & 477.34243 & $\begin{array}{l}476.32834 \\
478.52128\end{array}$ & $\begin{array}{l}(\mathrm{M}-\mathrm{H})- \\
(\mathrm{M}+\mathrm{H})+\end{array}$ & 512.30818 & (M-Cl)- \\
\hline 3 & SQ-29548 & 7.533 & 387.25943 & $\begin{array}{l}386.24580 \\
388.26556\end{array}$ & $\begin{array}{c}(\mathrm{M}-\mathrm{H})- \\
(\mathrm{M}+\mathrm{H})+\end{array}$ & $\begin{array}{l}422.22686 \\
410.25077 \\
426.22633 \\
\end{array}$ & $\begin{array}{c}(\mathrm{M}-\mathrm{Cl})- \\
(\mathrm{M}+\mathrm{Na})+ \\
(\mathrm{M}+\mathrm{K})+\end{array}$ \\
\hline 4 & U-46619 & 9.406 & 350.27918 & 349.27167 & (M-H)- & 385.25203 & $(\mathrm{M}+\mathrm{Cl})-$ \\
\hline
\end{tabular}



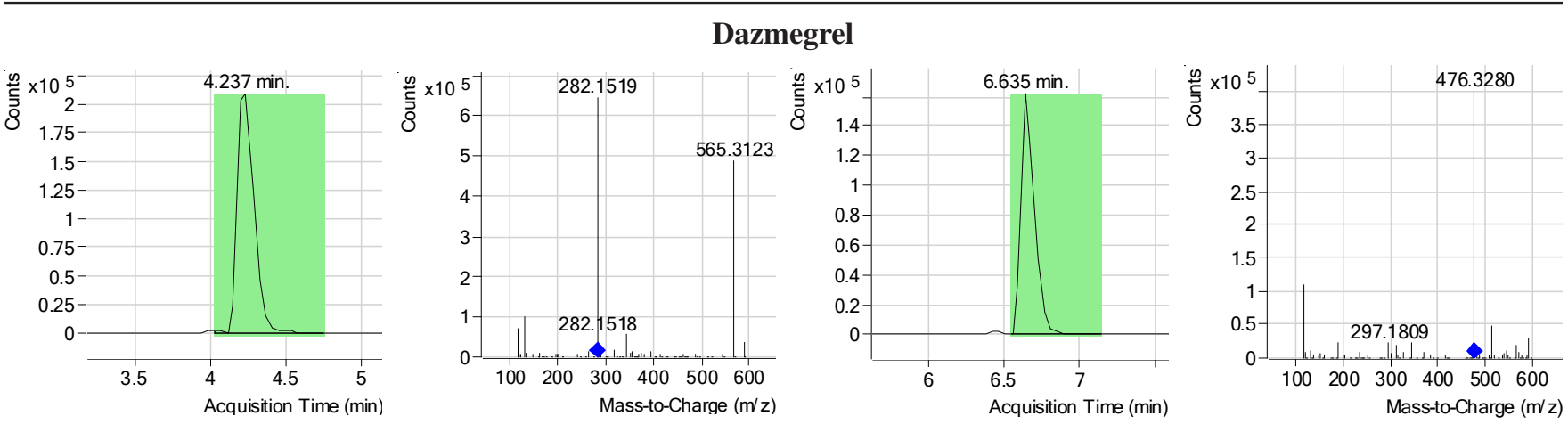

\section{SQ-29548}
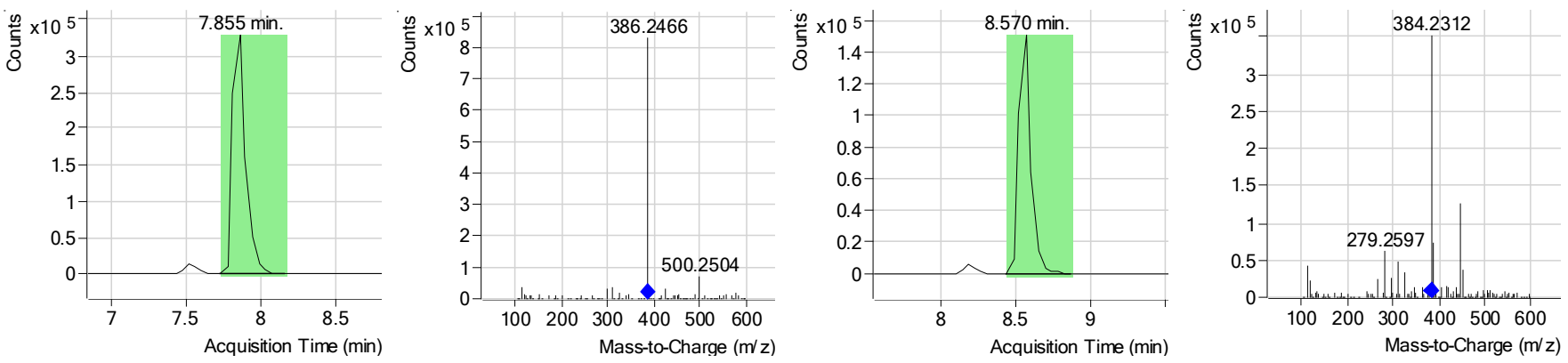

Fig. 1. HPLC-ESI-MS for the samples Dazmegrel, GR32191, SQ-29548 and U-46619 with Extraction ion current chromatogram (EIC) acquired in negative polarity scan mode and its ion chromatograms extracted at $\mathrm{m} / \mathrm{z}$ values corresponding polarity

TABLE-3

SYSTEM SUITABILITY PARAMETERS FOR THROMBOXANE RECEPTORS BY EIC CHROMATOGRAM

\begin{tabular}{lrrrr}
\hline Compound & Dazmegrel & GR 32191 & SQ-29548 & U-46619 \\
\hline RT & 4.237 & 6.635 & 7.855 & 8.57 \\
Area & 1581977 & 999300 & 2057000 & 936532 \\
Base Peak & 565.3119 & 476.32867 & 386.24651 & 384.23146 \\
k' $^{\prime}$ & -0.6 & -0.3 & -0.2 & -0.1 \\
Resolution & 51.1 & 14.5 & 2.2 & 2.6 \\
Tailing factor & 1 & 1.5 & 1.3 & 1.2 \\
Plates & 10437 & 25816 & 45679 & 59845 \\
Plates/M & 69580 & 172106.7 & 304526.7 & 398966.7 \\
Symmetry & 0.67 & 0.33 & 1 & 1 \\
SNR & 143.3 & 111.2 & 226.1 & 114.7 \\
\hline
\end{tabular}

As shown in Table-4, acceptable results of the regression analysis, the correlation coefficients $\left(\mathrm{r}^{2}\right)$, LODs and LOQs were obtained for all the analytes: all calibration curves showed good linear regression within the test ranges; the LODs and LOQs of the Dazmegrel, GR32191, SQ-29548 and U-46619 were in the range of 7.322-24.405 $\mu \mathrm{g} / \mathrm{mL}, 15.935-53.116 \mu \mathrm{g} /$ $\mathrm{mL}, 12.016-40.053116 \mu \mathrm{g} / \mathrm{mL}$ and $19.248-64.161 \mu \mathrm{g} / \mathrm{mL}$, respectively.

Precision and accuracy: Instrument precision was determined by performing injection repeatability test and the RSD value for Dazmegrel, GR32191, SQ-29548 and U-46619. The intra-day precision studies were carried out and RSD values were found to be $0.15-0.81,0.43-0.62,0.4-0.99$ and 0.61-1.2 \%; the inter-day precision studies were carried out and RSD values were found to be $0.61-1.54,0.62-1.00,0.38$ 1.7 and 76-1.14 \%, respectively (Table-5). The low RSD values indicate that the method is precise.

The accuracy of the method was determined by calculating recoveries of Dazmegrel, GR32191, SQ-29548 and U-46619 by method of standard addition. The recoveries found to be 94.42-101.08, 86.18-111.17, 90.47-109.44 and 103.93-109.45 $\%$, respectively (Table-6). The high values indicate that the method is accurate.

\section{Conclusion}

The proposed study describes qualitative LCMS method for estimation of Dazmegrel, GR32191, SQ-29548 and U-46619 in drug free human plasma. The method was validated and found to be very simple, sensitive accurate and precise. The simple liquid-liquid extraction method gave consistent and reproducible recoveries for the analytes from plasma. The method provided good linearity. The method is sensitive enough for quantitative detection of the analytes. Thus the proposed method can be used for routine analysis in clinical trials.

\section{ACKNOWLEDGEMENTS}

The authors are grateful to the Evolva Biotech Pvt. Ltd., India for providing laboratory facility for this research work

TABLE-4

LINEARITY, CALIBRATION DATA, LIMIT OF DETECTION AND LIMIT OF QUANTIFICATION

\begin{tabular}{|c|c|c|c|c|}
\hline Analyte & Calibration curve & Linearity $r^{2}$ & Limit of detection $(\mu \mathrm{g} / \mathrm{mL})$ & Limit of quantification $(\mu \mathrm{g} / \mathrm{mL})$ \\
\hline Dazmegrel & $Y=17436.389154 x+139624.144424$ & 0.95915301 & 7.322 & 24.405 \\
\hline GR32191 & $Y=10992.180210 x+74859.317172$ & 0.97292508 & 14.935 & 53.116 \\
\hline SQ-29548 & $Y=27724.437682 X-26335.089848$ & 0.97829994 & 12.016 & 40.053 \\
\hline U-46619 & $Y=9498.000625 x-132406.920330$ & 0.95860995 & 19.248 & 64.161 \\
\hline
\end{tabular}




\begin{tabular}{|c|c|c|c|c|c|c|c|}
\hline \multicolumn{8}{|c|}{$\begin{array}{l}\text { TABLE-5 } \\
\text { PRECISION AND ACCURACY DATA FOR THXA2 IN HUMAN PLASMA SAMPLES }\end{array}$} \\
\hline \multirow{2}{*}{ Analyte } & \multirow{2}{*}{$\begin{array}{l}\text { Concentration } \\
\text { (ppm) }\end{array}$} & \multicolumn{3}{|c|}{ Intra-day precision and accuracy $(n=6)$} & \multicolumn{3}{|c|}{ Inter-day precision and accuracy $(n=6)$} \\
\hline & & Concentration found & $\%$ RSD & Accuracy $(\%)$ & Concentration found & $\%$ RSD & Accuracy $(\%)$ \\
\hline \multirow{6}{*}{ Dazmegrel } & 10 & 10.6798 & 0.49 & 106.8 & 10.7885 & 0.61 & 107.88 \\
\hline & 20 & 21.5980 & 0.15 & 107.99 & 21.7469 & 1.54 & 108.73 \\
\hline & 30 & 30.6078 & 0.65 & 102.03 & 29.0150 & 0.85 & 96.72 \\
\hline & 40 & 39.4505 & 0.77 & 98.63 & 33.2873 & 0.77 & 83.22 \\
\hline & 50 & 53.7489 & 0.71 & 107.5 & 54.5627 & 0.80 & 109.13 \\
\hline & 60 & 62.6669 & 0.81 & 104.44 & 66.6823 & 1.14 & 111.14 \\
\hline \multirow{6}{*}{ GR32191 } & 10 & 9.9077 & 0.46 & 89.08 & 10.0560 & 0.62 & 100.56 \\
\hline & 20 & 22.1153 & 0.51 & 110.58 & 19.2492 & 1.00 & 96.25 \\
\hline & 30 & 32.3964 & 0.62 & 107.99 & 29.7122 & 0.69 & 99.04 \\
\hline & 40 & 38.0847 & 0.43 & 95.21 & 44.4189 & 0.97 & 111.05 \\
\hline & 50 & 49.7097 & 0.51 & 99.42 & 49.2728 & 0.82 & 98.55 \\
\hline & 60 & 60.5120 & 0.49 & 100.85 & 68.1045 & 0.74 & 113.51 \\
\hline \multirow{6}{*}{ SQ-29548 } & 10 & 9.0090 & 0.99 & 99.08 & 10.5151 & 1.70 & 105.15 \\
\hline & 20 & 18.9559 & 0.67 & 94.78 & 20.8421 & 0.40 & 104.21 \\
\hline & 30 & 30.0451 & 0.64 & 100.15 & 30.9363 & 0.82 & 103.12 \\
\hline & 40 & 36.1346 & 0.40 & 90.34 & 32.0568 & 0.38 & 80.14 \\
\hline & 50 & 52.5314 & 0.69 & 105.06 & 54.2367 & 0.61 & 108.47 \\
\hline & 60 & 63.6445 & 0.87 & 106.07 & 63.9918 & 0.98 & 106.65 \\
\hline \multirow{6}{*}{ U-46619 } & 10 & 11.1123 & 0.61 & 111.12 & 11.9183 & 0.86 & 119.18 \\
\hline & 20 & 17.0481 & 1.20 & 85.24 & 20.5693 & 0.75 & 102.85 \\
\hline & 30 & 26.4533 & 0.89 & 88.18 & 24.6241 & 0.88 & 82.08 \\
\hline & 40 & 34.4475 & 0.97 & 86.12 & 38.8392 & 0.76 & 97.10 \\
\hline & 50 & 45.2124 & 0.89 & 90.42 & 43.5963 & 1.02 & 87.19 \\
\hline & 60 & 55.7526 & 0.93 & 92.92 & 53.5268 & 1.14 & 89.21 \\
\hline
\end{tabular}

\begin{tabular}{cccc}
\multicolumn{5}{c}{ TABLE-6 } \\
\multicolumn{5}{c}{$\begin{array}{c}\text { RECOVERY DATA OF STANDARD SOLUTIONS } \\
\text { ADDED TO THE SAMPLES ANALYZED USING } \\
\\
\text { THE PROPOSED HPLC METHODS }\end{array}$} \\
\hline \multirow{2}{*}{ Analyte } & $\begin{array}{c}\text { Added } \\
(\mu \mathrm{g} / \mathrm{mL})\end{array}$ & $\begin{array}{c}\text { Measured } \\
(\mu \mathrm{g} / \mathrm{mL})\end{array}$ & $\begin{array}{c}\text { Recovery } \% \\
(\mathrm{mean} \pm \mathrm{SD})\end{array}$ \\
\hline \multirow{3}{*}{ Dazmegrel } & 100 & 100.2638 & $100.26 \pm 9.85$ \\
& 125 & 118.0194 & $94.42 \pm 15.82$ \\
& 250 & 252.7091 & $101.08 \pm 10.00$ \\
\hline \multirow{3}{*}{ GR32191 } & 100 & 86.1809 & $86.18 \pm 10.41$ \\
& 125 & 125.7788 & $100.62 \pm 20.82$ \\
& 250 & 277.9137 & $111.17 \pm 17.32$ \\
\hline \multirow{3}{*}{ SQ-29548 } & 100 & 105.1364 & $105.14 \pm 11.55$ \\
& 125 & 136.8009 & $109.44 \pm 20.00$ \\
& 250 & 226.1709 & $90.47 \pm 15.28$ \\
\hline \multirow{3}{*}{ U-46619 } & 100 & 103.9274 & $103.93 \pm 15.28$ \\
& 125 & 136.8080 & $109.45 \pm 20.01$ \\
& 250 & 265.9903 & $106.40 \pm 20.13$ \\
\hline
\end{tabular}

and Holy Mother Diagnostics and Blood Bank (Chennai, India) for providing human plasma.

\section{REFERENCES}

1. M.V. Rebec and V.A. Skrinska, J. Chromatogr., 432, 375 (1988).

2. G.T. Swayne, J. Maguire, J. Dolan, P. Raval, G. Dane, M. Greener and D.A. Owen, Eur. J. Pharmacol., 152, 311 (1988).
3. R.P. Gladue and M.F. Newborg, Transplantation, 52, 837 (1991).

4. P. Lumley, B.P. White and P.P. Humphrey, Br. J. Pharmacol., 97, 783 (1989).

5. M.R. Foster, E.J. Hornby and L.E. Stratton, Thromb. Res., 65, 769 (1992).

6. M. Thomas, R.J. Keery, M.K. Charter, N.L. Scully, J.E. Chilton and P. Lumley, Br. J. Clin. Pharmacol., 32, 181 (1991).

7. R.L. Lorenz, S. Fischer, W. Wober, H.A. Wagner and P.C. Weber, Biochem. Pharmacol., 35, 761 (1986).

8. J.M. Ritter, N. Benjamin, H.S. Doktor, S.E. Barrow, T.G. Mant, S. Schey and P. Stewart-Long, Br. J. Clin. Pharmacol., 29, 431 (1990).

9. T. Uematsu, S. Nagashima, A. Mizuno, K. Hirano and M. Nakashima, J. Clin. Pharmacol., 31, 815 (1991).

10. R.C. Beasley, R.L. Featherstone, M.K. Church, P. Rafferty, J.G. Varley, A. Harris, C. Robinson and S.T. Holgate, J. Appl. Physiol., 66, 1685 (1989).

11. D. Zhu, M. Bousamra, D.C. Zeldin, J.R. Falck, M. Townsley, D.R. Harder, R.J. Roman and E.R. Jacobs, Am. J. Physiol. Lung Cell Mol. Physiol., 278, L335 (2000).

12. D.W. Phillipson, A.A. Tymiak, J.G. Tuttle, K.S. Hartl, T.W. Harper, M.S. Bolgar, G.T. Allen and M.L. Ogletree, J. Lipid Mediat., 7, 155 (1993).

13. C.H. Yeh, H.C. Peng, J.B. Yih and T.F. Huang, Biochim. Biophys. Acta, 1425, 493 (1998).

14. P.A. Modesti, A. Colella, R. Abbate, G. Gensini and G.N. Serneri, Eur. J. Pharmacol., 169, 85 (1989).

15. S.J. MacLennan and G.R. Martin, Br. J. Pharmacol., 107, 418 (1992).

16. E.J. Kattelman, D.L. Venton and G.C. Le Breton, Thromb. Res., 41, 471 (1986). 